\title{
Participation of metabolic activation of 2,4,6-trinitrotoluene to 4-hydroxylamino-2,6-dinitrotoluene in hematotoxicity
}

\author{
Yasuhiro Shinkai ${ }^{1}$, Song $\mathrm{Li}^{2}$, Tomohiro Kikuchi ${ }^{3}$ and Yoshito Kumagai ${ }^{1}$
}

\author{
${ }^{1}$ Environmental Biology Laboratory, Faculty of Medicine, University of Tsukuba, \\ 1-1-1 Tennodai, Tsukuba, Ibaraki 305-8575, Japan \\ ${ }^{2}$ Doctoral Program in Medical Sciences, University of Tsukuba, 1-1-1 Tennodai, Tsukuba, Ibaraki 305-8575, Japan \\ ${ }^{3}$ Master's program in Environmental Sciences, University of Tsukuba, 1-1-1 Tennodai, Tsukuba, Ibaraki 305-8575, Japan
}

(Received May 20, 2015; Accepted July 8, 2015)

\begin{abstract}
Exposure to 2,4,6-trinitrotoluene (TNT) causes methemoglobin (metHb) formation, hemolysis and negative heme balance in vivo, but the mechanistic details are poorly understood. In the present study, we examined the participation of metabolic activation in TNT-mediated hematotoxicity. Exposure of rats with TNT $(300 \mathrm{mg} / \mathrm{kg}$, i.p.) for 4 days resulted in a decrease of hematocrit value coupled to an increase in metHb formation. The red blood cells treated with 4-hydroxylamino-2,6-dinitrotoluene (HADNT), a metabolite of TNT, underwent readily hemolysis in vitro, whereas such a phenomenon was not seen with TNT. Consistent with this, HADNT is active toward metHb formation and the decrease in thiol content of the globin moiety compared with TNT and its metabolites 4-amino-2,6-dinitrotoluene (ADNT) and 4-acetylamino-2,6-dinitrotoluene (AADNT). Furthermore, interaction of purified rat oxyhemoglobin (oxyHb) with HADNT, but not TNT, ADNT, and AADNT, caused a concentration-dependent production of $\mathrm{H}_{2} \mathrm{O}_{2}$ and ferrylhemoglobin (ferrylHb) which is a highly oxidizing state formed by reaction of oxyHb with $\mathrm{H}_{2} \mathrm{O}_{2}$. Notably, hemin was released during interaction of oxyHb with HADNT. Taken together, these findings suggest that HADNT is an active metabolite that mediates TNT-induced hematotoxicity via formation of prooxidants such as $\mathrm{H}_{2} \mathrm{O}_{2}$ and ferrylHb.
\end{abstract}

Key words: 2,4,6-Trinitrotoluene, Metabolic activation, Hemoglobin, Hematotoxicity, Hydrogen peroxide

\section{INTRODUCTION}

Nitroaromatics are important precursors for the synthesis of a wide variety of industrial chemicals such as munitions, pesticides, herbicides, and dyes. Their widespread use has led to environmental contamination, and nitroaromatics are recognized as priority pollutants, due to their toxicity (Kovacic and Somanathan, 2014). 2,4,6Trinitrotoluene (TNT) has been used as a military explosive. Acute and chronic exposures of workers to TNT have been shown to cause toxicity in the liver, the hematopoietic system and the eye (Härkönen et al., 1983; Hathaway, 1977; Sabbioni et al., 2005). Hematotoxic action of TNT is manifested as hemolysis, destruction of hemoglobin $(\mathrm{Hb})$ in erythrocytes, formation of methemoglobin (metHb), and/or formation of sulfhemoglobin (sulfHb) (Crawford, 1954; Djerassi and Vitany, 1975; Levine et al., 1984). Tenhunen et al. (1984) and Savolainen et al. (1985) reported that exposure of rats or humans to TNT resulted in the reduction of the enzyme activity responsible for synthesis of delta-aminolevulinic acid which is an intermediate for heme synthesis, but increased the heme oxygenase activity. Although these findings suggest that TNT is associated with negative heme balance, no mechanistic details to clarify these observations have been reported.

The metabolism of TNT has been extensively studied because it is recognized that most nitroaromatic compounds require reductive activation (Biaglow et al., 1986; Kappus, 1986) to exhibit hematotoxic actions. With experimental animals, it was found that TNT is primarily metabolized by a reductive pathway to form the hydroxylamines, which are further reduced to the respective amines or diamino derivatives (Channon et al., 1944). These metabolites were also identified in urine of munition workers (Ahlborg et al., 1988; Woollen et al., 1986). Leung et al. (1995) showed that microsomal enzymes are capable of biotransforming 4-hydroxyamino-2,6-dinitrotoluene (HADNT) and 4-amino-2,6-dinitrotoluene (ADNT) from TNT. Recently, we have iden-

Correspondence: Yoshito Kumagai (E-mail: yk-em-tu@md.tsukuba.ac.jp) 
tified NADPH-cytochrome P450 reductase (P450R) from rat liver as an enzyme responsible for catalyzing the reduction of TNT to HADNT, leading to release of nitrite via chemical interaction of HADNT and TNT (Shinkai et al. unpublished observation). We also reported that ADNT is further metabolized to 4-acetylamino-2,6-dinitrotolune (AADNT) by $\mathrm{N}$-acetyltransferase in cytosolic enzymes from rat liver in the presence of acetyl CoA (Li et al., 1998).

With respect to hematologic toxicity, redox processes of $\mathrm{Hb}$ have been linked to the toxic effects of drugs and to the accelerated aging of red blood cells (Beutler, 1969). In erythrocytes, $\mathrm{Hb}$ is protected against oxidative damage by reactive oxygen species; however, under certain conditions $\mathrm{Hb}$ is susceptible to oxidative damage associated with elevation of hydrogen peroxide $\left(\mathrm{H}_{2} \mathrm{O}_{2}\right)$ (Hebbel and Eaton, 1989; Schacter, 1986). Reaction with $\mathrm{H}_{2} \mathrm{O}_{2}$ can transform oxyhemoglobin (oxyHb) and metHb into a higher oxidation state, ferrylhemoglobin (ferrylHb) (Kanias and Acker, 2010). Although toxic actions of TNT have been extensively studied, the role of metabolic activation in TNT-induced hematotoxicity involved in oxidative stress is poorly understood. In the present study, we explored the participation of TNT metabolites in TNTmediated hematotoxic action in vivo and in vitro.

\section{MATERIALS AND METHODS}

\section{Materials}

Ferriproporphyrin IX (hemin), hemoglobin (from human erythrocytes) and catalase were obtained from Sigma-Aldrich Co. (St, Louis, MO, USA). Sodium azide and 5,5'-dithiobis (2-nitrobenzoic acid) were obtained from Nacalai Tesque (Kyoto, Japan). DEAE-Sephadex A-50 and Sephadex G-100 were purchased from Pharmacia LKB Biotechnology (Uppsala, Sweden). All other chemicals used were of the highest grade available. TNT was synthesized from 2,4-dinitrotoluene by the method of MacGookin et al. (1940). HADNT and ADNT were synthesized by reduction of TNT under hydrogen sulfide gas and separated by silica gel column chromatography with different ratios of benzene to ethyl acetate as a solvent. Finally, HADNT and ADNT were recrystallized with 1,1,1-trichloroethane and ethanol, respective1y. 4-Acetylamino-2,6-dinitrotoluene (AADNT) was synthesized from ADNT with acetic anhydride. These synthetic compounds showed $>95 \%$ purity. The chemical structures of TNT, HADNT, ADNT and AADNT characterized by CI-MS analysis, NMR, and IR spectroscopy were as follows. TNT: $m / z 228\left(\mathrm{MH}^{+}\right)$; ${ }^{1} \mathrm{H}-\mathrm{NMR}$ (ppm) $2.58(3 \mathrm{H}, \mathrm{s}), 9.02(2 \mathrm{H}, \mathrm{s})$; IR $\left(\mathrm{KBr}, \mathrm{cm}^{-1}\right)$ 1,540 $\left(-\mathrm{NO}_{2}\right)$,
1,353 (-NO $)$; HADNT: $m / z 214\left(\mathrm{MH}^{+}\right) ;{ }^{1} \mathrm{H}-\mathrm{NMR}$ (ppm) $2.30(3 \mathrm{H}, \mathrm{s}), 7.51(2 \mathrm{H}, \mathrm{s}), 9.00(1 \mathrm{H}$, br s), $9.14(1 \mathrm{H}$, br s); IR $\left(\mathrm{KBr}, \mathrm{cm}^{-1}\right)$ 3,348 (-OH), 3,291 (-NH), 1,535 (-NO $\left.)_{2}\right)$, 1,342 (-NO $)_{2}$; ADNT: $m / z 198\left(\mathrm{MH}^{+}\right)$; ${ }^{1} \mathrm{H}-\mathrm{NMR}(\mathrm{ppm})$ $2.23(3 \mathrm{H}, \mathrm{s}), 6.16(2 \mathrm{H}, \mathrm{s}), 7.30(2 \mathrm{H}, \mathrm{s})$; IR $\left(\mathrm{KBr}, \mathrm{cm}^{-1}\right)$ 3,482 $\left(-\mathrm{NH}_{2}\right), 3,382\left(-\mathrm{NH}_{2}\right), 1,535\left(-\mathrm{NO}_{2}\right), 1,357\left(-\mathrm{NO}_{2}\right)$; AADNT: $m / z 240\left(\mathrm{MH}^{+}\right)$; ${ }^{1} \mathrm{H}-\mathrm{NMR}(\mathrm{ppm}) 2.11(3 \mathrm{H}, \mathrm{s})$, $2.40(2 \mathrm{H}, \mathrm{s}), 8.38(2 \mathrm{H}, \mathrm{s}), 10.68(1 \mathrm{H}, \mathrm{s})$; IR $\left(\mathrm{KBr}, \mathrm{cm}^{-1}\right)$ $1,683(-\mathrm{C}=\mathrm{O}), 1,540\left(-\mathrm{NO}_{2}\right), 1,356\left(-\mathrm{NO}_{2}\right)$. IR spectroscopy was carried out with a JASCO FT/IR-7300 instrument, NMR-spectra were recorded with a JNM-EX270, and mass spectra with a Shimazu QP-1000 instrument.

\section{Treatment of animals}

Male Fischer 344 (F344) rats (7 weeks, Clea Japan, Inc., Tokyo, Japan) were used. The animals were housed in an air-conditioned room $\left(25^{\circ} \mathrm{C}\right)$ with a $12 \mathrm{hr}$ light/dark cycle. They were allowed free access to water and food. The animals were orally administered TNT (300 mg/kg/ day, suspended in corn oil) for 4 days. At $1 \mathrm{hr}$ after final injection of TNT, the animals were sacrificed and the blood was collected. Control animals received the same treatment without exposure to TNT. The hematocrit (Ht) value was measured by using microcapillary tube centrifugation.

\section{Hemolysis of erythrocytes by TNT and its metabolites}

Freshly drawn rat blood was centrifuged at $500 \mathrm{~g}$ for $10 \mathrm{~min}$ at $4^{\circ} \mathrm{C}$. After removal of plasma and white buffy coat, the cells were washed three times with $0.9 \%$ $\mathrm{NaCl}$. Cell suspensions were prepared at $20 \%$ in phosphate-buffered saline $(10 \mathrm{mM}$ potassium phosphate (pH 7.4)-139 mM NaCl). The final suspensions (10\%) were incubated with TNT, ADNT, HADNT and AADNT with the indicated concentrations at $37^{\circ} \mathrm{C}$ for $60 \mathrm{~min}$ in a shaking water bath. For the controls, a similar incubation mixture without TNT and its metabolites or acetone was used. Percent hemolysis was determined as $100 \times \mathrm{A} / 10 \mathrm{~A}_{100 \%}$, where $\mathrm{A}$ is the absorbance of the peak of Soret band of hemoglobin present in the supernatant of the red blood cell suspension after centrifugation, and $\mathrm{A}_{100 \%}$ is the absorbance at the peak of the Soret band present in the entire red blood cell suspension after 10 -fold dilution with distilled water.

\section{Preparation of oxyHb and metHb}

$\mathrm{OxyHb}$ was purified from the hemolysate as described by Winterbourn (Winterbourn, 1990). Erythrocytes were collected from male F344 rats and washed three times with 2 volumes $0.9 \% \mathrm{NaCl}$. The erythrocytes were lyzed by addition of 2 volumes of distilled water and then the hemolysate was centrifuged at 29,000 $\mathrm{g}$ for $40 \mathrm{~min}$ to 
Interaction of hemoglobin with TNT metabolites

remove cell membranes, white blood cells and platelets. Supernatants obtained $(94 \mathrm{~mL})$ were dialyzed overnight against $5,000 \mathrm{~mL}$ of $5 \mathrm{mM}$ Tris- $\mathrm{HCl}\left(\mathrm{pH} \mathrm{8.6)}\right.$ at $4^{\circ} \mathrm{C}$. The dialyzed sample was concentrated to $107 \mathrm{~mL}$ using an Amicon ultrafiltration system with a YM-10 membrane. The concentrated sample was applied on a DEAE Sephadex A-50 column ( $23 \times 5 \mathrm{~cm}$, i.d.), which had been equilibrated with $5 \mathrm{mM}$ Tris- $\mathrm{HCl}$ buffer $(\mathrm{pH} \mathrm{8.6)}$ at a flow rate of $120 \mathrm{~mL} / \mathrm{hr}$. The column was washed with the same buffer until the eluate was clear. $\mathrm{OxyHb}$ was eluted with $10 \mathrm{mM}$ Tris- $\mathrm{HCl}$ buffer ( $\mathrm{pH} 7.1$ )- $40 \mathrm{mM} \mathrm{NaCl}$. Fractions (397 mL) containing oxyHb were combined and concentrated to $49 \mathrm{~mL}$. The concentrated sample was applied on a Sephadex G-100 column (65 x 5 cm, i.d.), which had been equilibrated with $50 \mathrm{mM}$ potassium phosphate (pH 7.0)-0.15 M KCl. OxyHb fractions were combined and dialyzed against $3,000 \mathrm{~mL}$ of $50 \mathrm{mM}$ potassium phosphate ( $\mathrm{pH}$ 7.0) buffer. Resulting samples showed two bands based on alpha- and beta-chains of $\mathrm{Hb}$ with molecular weights of $14.5 \mathrm{kDa}$ and $16 \mathrm{kDa}$, respectively, on SDS-PAGE and were free of catalase and superoxide dismutase. The final preparation of oxyHb was mixed at a sodium dithionite $/ \mathrm{Hb}$ molar ratio of 1.2 for $15 \mathrm{hr}$ at $4^{\circ} \mathrm{C}$ to reduce the ferrous form completely because most of the oxyHb was converted to metHb during purification. The mixture was passed through an Econo-Pack 10DG column (Bio-Rad) to remove unreacted dithionite. To prepare metHb, oxyHb was mixed with potassium ferricyanide at a 2 -fold excess for $15 \mathrm{hr}$ at $4^{\circ} \mathrm{C}$. Unreacted potassium ferricyanide was removed by the same method as described above for preparation of oxyHb. Concentrations of oxyHb and metHb were determined by the method of Evelyn and Malloy (Evelyn and Malloy, 1938).

\section{Formation of prooxidants}

$\mathrm{H}_{2} \mathrm{O}_{2}$ generation was determined by the method of Hildebrandt and Roots (Hildebraunt and Roots, 1975). Incubation mixture $(0.2 \mathrm{~mL})$ consisted of $10 \mu \mathrm{M}$ oxy$\mathrm{Hb}$, indicated concentrations of TNT or its metabolites, $0.2 \mathrm{mM}$ sodium azide and $20 \mathrm{mM}$ potassium phosphate buffer ( $\mathrm{pH} 7.0)$. The reaction mixture was preincubated with sodium azide, and then reaction was initiated by addition of TNT or its metabolites. After incubations were carried out at $25^{\circ} \mathrm{C}$ for $30 \mathrm{~min}$, reactions were terminated by addition of perchloric acid (final $2.5 \%$ ). Then the mixtures were centrifuged at $15,000 \mathrm{~g}$ for $10 \mathrm{~min}$. The each supernatant $(0.2 \mathrm{~mL})$ was transferred to test tubes to which were added $10 \mathrm{mM}$ ferrous ammonium sulfate $(0.24 \mathrm{~mL})$ and $2.5 \mathrm{M}$ potassium thiocyanate $(0.12 \mathrm{~mL})$. The formation of $\mathrm{Fe}(\mathrm{SCN})_{3}$ was measured at $480 \mathrm{~nm}$.

FerrylHb formation was determined according to the method of Giuliv and Davies (1990). Optical absorption spectra were recorded in a Shimadzu UV-1600 spectrophotometer (Kyoto, Japan). OxyHb $(80 \mu \mathrm{M})$ was incubated with indicated concentrations of TNT or its metabolites and $20 \mathrm{mM}$ potassium phosphate buffer $(\mathrm{pH}$ 7.0) in a total volume of $0.2 \mathrm{~mL}$ at $25^{\circ} \mathrm{C}$. The formation of ferryl $\mathrm{Hb}$ was calculated with the absorption coefficients as reported by Yoshida et al. (1994). FerrylHb was also detected by its reaction with sodium sulfide to convert into sulfHb (Giulivi and Davies, 1990). Briefly, sodium sulfide ( $2 \mathrm{mM}$ ) was added to the reaction mixture and sulfHb formation was determined at $620 \mathrm{~nm}$ after incubation for $15 \mathrm{~min}$.

\section{Sulfhydryl content}

Concentrations of the sulfhydryl groups in oxyHb were determined as reported previously (Kumagai et al., 1990). The incubation mixture $(0.2 \mathrm{~mL})$ consisted of $10 \mu \mathrm{M}$ oxy$\mathrm{Hb}, 25 \mu \mathrm{M}$ TNT or its metabolites and $10 \mathrm{mM}$ potassium phosphate buffer ( $\mathrm{pH} 7.0)$. After the reaction at $25^{\circ} \mathrm{C}$ for $30 \mathrm{~min}$, each aliquot $(0.1 \mathrm{~mL})$ of the reaction mixture was mixed with $0.3 \mathrm{~mL}$ of $0.2 \mathrm{M}$ Tris- $\mathrm{HCl}(\mathrm{pH} 8.2)-20 \mathrm{mM}$ EDTA, $20 \mu \mathrm{L}$ of $10 \mathrm{mM}$ 5,5'-dithiobis(2-nitrobenzoic acid), and $0.15 \mathrm{~mL}$ of 5\% SDS. After mixing, the absorbance at $412 \mathrm{~nm}$ was measured against a blank reagent to determine the total sulfhydryls, using an extinction coefficient of $13.6 \mathrm{mM}^{-1} \mathrm{~cm}^{-1}$.

\section{Detection of hemin}

Release of hemin was determined by the method of Liu et al. (1988). OxyHb $(25 \mu \mathrm{M})$ was incubated with TNT or its metabolites in $20 \mathrm{mM}$ potassium phosphate buffer $\left(\mathrm{pH} \mathrm{7.0)}\right.$ at $25^{\circ} \mathrm{C}$ for the indicated times. After the reaction, $\mathrm{NaCl}$ was added to the reaction mixtures to make a final concentration of $1.5 \mathrm{M}$. Aliquots (1 mL) were applied on a Dowex AG 1-X8 column (1 mL volume), which had been equilibrated with $10 \mathrm{mM}$ potassium phosphate buffer ( $\mathrm{pH} 7.8$ )-1.5 M NaCl. The column was extensively washed with $20 \mathrm{~mL}$ of the same buffer to remove oxyHb. Hemin was eluted with $2 \mathrm{~mL}$ of $5 \%$ SDS. The concentration of hemin was determined spectrophotometrically at $385 \mathrm{~nm}$ using an extinction coefficient of $58.4 \mathrm{mM}^{-1} \mathrm{~cm}^{-1}$.

\section{HPLC analysis}

For measurement of HADNT, Shimadzu HPLC system was used. After the addition of 2.5\% TCA, an aliquot $(50 \mu \mathrm{L})$ was applied to a YMC packed column AM-type $(250 \times 4.6 \mathrm{~mm}$ i.d., $5 \mu \mathrm{m}$ particle size, Kyoto, Japan $)$ at a flow rate of $1 \mathrm{~mL} / \mathrm{min}$. HADNT was detected at $255 \mathrm{~nm}$ and water/acetonitrile $(1: 1, \mathrm{v} / \mathrm{v})$ was used as the mobile phase. 


\section{Statistical analysis}

Statistical significance was assessed with Student's t-test, and $\mathrm{p}<0.05$ was considered significant.

\section{RESULTS}

\section{Hematotoxicity caused by TNT exposure in vivo}

We first examined the effect of TNT on hematotoxicity in vivo. Exposure of rats to TNT $(300 \mathrm{mg} / \mathrm{kg} /$ day $)$ by oral administration for 4 days resulted in a significant decrease in the $\mathrm{Ht}$ value and increase in metHb formation at $1 \mathrm{hr}$ after the final administration (Fig. 1), suggesting that TNT exhibits hematotoxicity and decreases red blood cells in vivo.

\section{Hematotoxic effects of TNT and its metabolites in vitro}

We described the chemical structure of TNT and its metabolites we examined in this study (Fig. 2A). To compare the hematotoxicity among these compounds, we performed in vitro experiments. As shown in Fig. 2B, incubation of HADNT with the erythrocytes at $37^{\circ} \mathrm{C}$ for 60 min caused a significant elevated hemolysis in a concentration-dependent manner. Little appreciable hemolysis was seen when the erythrocytes incubated with TNT at concentration $0.5 \mathrm{mM}$ (Fig. 2B), suggesting that TNTmediated hematotoxicity observed in vivo may require a reductive transformation to HADNT. Consistent with this notion, HADNT significantly stimulated metHb formation as well, whereas TNT, ADNT and AADNT did not (Fig. 2C). Formation of metHb following incubation of HADNT with oxyHb increased with HADNT concentrations up to $0.5 \mathrm{mM}$ (data not shown). It has been

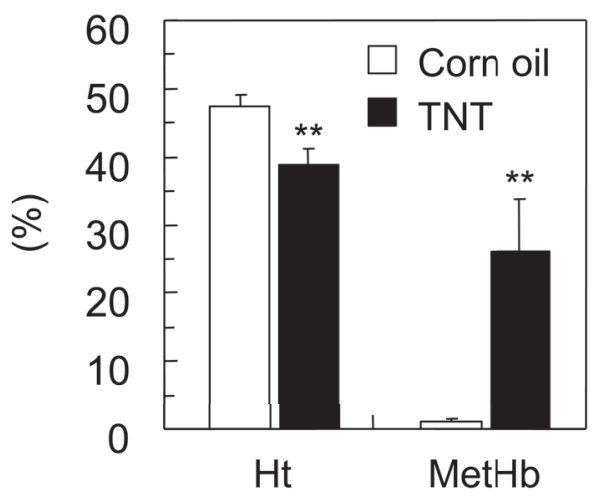

Fig. 1. TNT causes the decrease in $\mathrm{Ht}$ value and the increase in metHb formation in vivo. TNT $(300 \mathrm{mg} / \mathrm{kg})$ was administrated orally to rats for 4 days and then sacrificed $1 \mathrm{hr}$ after injection. Each data is the mean \pm S.D. of three to four animals. ${ }^{* *}, \mathrm{P}<0.01$ compared with corn oil. reported that hydroxylamine and its derivatives are reactive towards oxyHb to form metHb and $\mathrm{H}_{2} \mathrm{O}_{2}$ (Spooren and Evelo, 2000). If $\mathrm{H}_{2} \mathrm{O}_{2}$ is produced during incubation of HADNT with oxyHb, sulhydryl contents would be decreased because of its oxidation. As expected, although the reaction of either TNT or ADNT reduced the thiol content of oxyHb significantly, HADNT was the most effective agent for decrease in the SH groups (Fig. 2D); the consumption of oxyHb sulhydryls showed a concentration-dependent reaction up to $50 \mu \mathrm{M}$ (data not shown). These results support our hypothesis that metabolic activation of TNT to HADNT is involved in the hematotoxic actions of TNT in vivo.

\section{Generation of $\mathrm{H}_{2} \mathrm{O}_{2}$ during interaction of oxyHb}

Consistent with the results of thiol content, incubation of HADNT with oxyHb $\left(25^{\circ} \mathrm{C}\right.$ for $\left.10 \mathrm{~min}\right)$ resulted in a production of $\mathrm{H}_{2} \mathrm{O}_{2}$ in a concentration-dependent fashion (10 $\mu \mathrm{M}$ HADNT, $14.5 \mu \mathrm{M} ; 100 \mu \mathrm{M}$ HADNT, $21.2 \mu \mathrm{M}$; $1000 \mu \mathrm{M}$ HADNT, $32.3 \mu \mathrm{M}$ ). However, there was minimal generation of $\mathrm{H}_{2} \mathrm{O}_{2}$ by reactions with TNT, ADNT and AADNT as shown in Table 1 . The produced $\mathrm{H}_{2} \mathrm{O}_{2}$ was completely abolished by addition of catalase. Under these conditions, no superoxide or thiyl radical was seen using ESR spectrometry (data not shown).

Since $\mathrm{H}_{2} \mathrm{O}_{2}$, generated within red blood cells, can undergo a variety of reactions, one of which is with oxy$\mathrm{Hb}$ to form ferryl heme species (Giulivi and Davies, $1990)$, formation of ferrylHb by reaction of oxy Hb $(80 \mu \mathrm{M})$ with different concentrations of HADNT $\left(25^{\circ} \mathrm{C}\right.$, $10 \mathrm{~min}$ ) was examined (Fig. 3A). FerrylHb was produced in a concentration-dependent manner and reached a plateau level at $0.5 \mathrm{mM}$. When the concentration of HAD$\mathrm{NT}$ was fixed at $1 \mathrm{mM}$, ferrylHb formation increased to $5 \mathrm{~min}$ and the steady-state level was maintained during the reaction up to $15 \mathrm{~min}$ (data not shown). In contrast, negligible formation of ferrylHb during incubation of oxyHb with TNT, ADNT or AADNT was detected under these conditions (data not shown). To confirm whether ferryl $\mathrm{Hb}$ was formed as an intermediate in the reaction of oxyHb with HADNT, sodium sulfide (2 mM) was added to the incubation mixture, because sodium sulfide has been used to trap the ferryl oxidation state of hemoglobin (Giulivi and Davies, 1990). As expected, the appearance of a new peak at $622 \mathrm{~nm}$, corresponding to the formation of sulfHb (Berzofsky et al., 1971), accompanied with a decreased absorbance maximum at $543 \mathrm{~nm}$ and $575 \mathrm{~nm}$, which corresponds to oxyHb, was observed (Fig. 3B). 
Interaction of hemoglobin with TNT metabolites<smiles>Cc1c([N+](=O)[O-])cc([N+](=O)[O-])cc1[N+](=O)[O-]</smiles>

TNT<smiles>Cc1c([N+](=O)[O-])cc(N)cc1[N+](=O)[O-]</smiles>

HADNT<smiles>Cc1c([N+](=O)[O-])cc(N)cc1[N+](=O)[O-]</smiles>

ADNT<smiles>CC(=O)Nc1cc([N+](=O)[O-])c(C)c([N+](=O)[O-])c1</smiles>

AADNT

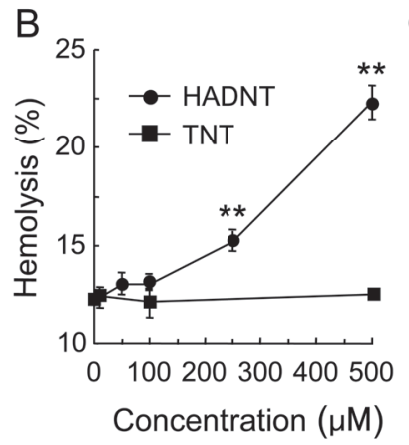

C

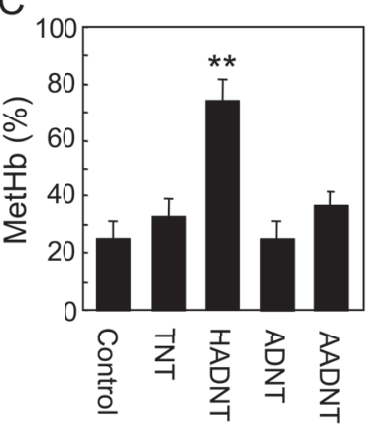

D

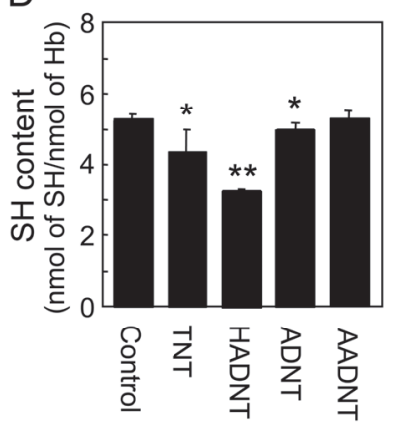

Fig. 2. Effects of TNT and its metabolites on hematotoxic actions in vitro. A. Chemical structures of TNT and its metabolites. B. Effects of TNT and HADNT on hemolysis in rat erythrocytes. Hemolysis of $10 \%$ suspensions of erythrocytes was determined after incubation for $1 \mathrm{hr}$ at $37^{\circ} \mathrm{C}$ in the presence of TNT or HADNT. Measurement of hemolysis was performed as described in Materials and Methods. Each point is the mean \pm S.D. of three determinations. C. MetHb formation following incubation of purified oxyHb with TNT and its metabolites in vitro. OxyHb $(0.1 \mathrm{mM})$ was incubated with TNT and its metabolites $(0.2 \mathrm{mM})$ in $10 \mathrm{mM} \mathrm{KPi}(\mathrm{pH} 7.0)$ at $25^{\circ} \mathrm{C}$ for $30 \mathrm{~min}$, and then metHb was measured. Each value is the mean \pm S.D. of four determinations. D. Decrease in thiol groups of $\mathrm{Hb}$ following incubation of purified oxyHb with TNT and its metabolites in vitro. Oxy$\mathrm{Hb}(10 \mu \mathrm{M})$ was incubated with TNT and its metabolites $(25 \mu \mathrm{M})$ in $10 \mathrm{mM} \mathrm{KPi}(\mathrm{pH} 7.0)$ at $25^{\circ} \mathrm{C}$ for $30 \mathrm{~min}$, and then the sulfhydryl content was measured. Each value is the mean \pm S.D. of four determinations. ${ }^{*}, \mathrm{P}<0.05 ;^{* *}, \mathrm{P}<0.01$ compared with control. Acetone (with rat erythrocytes) or dimethyl sulfoxide (with oxyHb) was used as control.

Table 1. Generation of hydrogen peroxide during incubation of oxyHb with TNT and its metabolites.

\begin{tabular}{lc}
\hline Compounds & $\mathrm{H}_{2} \mathrm{O}_{2}(\mu \mathrm{M})$ \\
\hline TNT & $0.6 \pm 1.0$ \\
HADNT & $32.3 \pm 2.8$ \\
ADNT & $1.2 \pm 0.5$ \\
AADNT & n.d. \\
\hline
\end{tabular}

OxyHb $(10 \mu \mathrm{M})$ was incubated with $1 \mathrm{mM}$ of TNT or its metabolites at $25^{\circ} \mathrm{C}$ for $10 \mathrm{~min}$ in $20 \mathrm{mM} \mathrm{KPi}(\mathrm{pH} 7.0)-0.2 \mathrm{mM}$ $\mathrm{NaN}_{3}$. Each data is the mean \pm S.D. of three determinations. Each compound was dissolved in dimethyl sulfoxide and $\mathrm{H}_{2} \mathrm{O}_{2}$ formation was estimated by deducing $\mathrm{H}_{2} \mathrm{O}_{2}$ formed with dimethyl sulfoxide $(5.2 \mu \mathrm{M})$. n.d., not detectable.

\section{Heme release during interaction of $\mathrm{Hb}$ with HADNT}

From the results so far, it is suggested that HADNT is a reactive metabolite to produce $\mathrm{H}_{2} \mathrm{O}_{2}$ in the presence of $\mathrm{Hb}$ species, resulting in ferrylHb formation. Since it has been shown that $\mathrm{H}_{2} \mathrm{O}_{2}$ is able to release the heme moiety from hemoprotein (Balla et al., 1993; Karuzina et al., 1999), we monitored hemin release during the reaction of oxyHb $(25 \mu \mathrm{M})$ with HADNT (Fig. 4). As expect- ed, HADNT $(0.1$ or $1 \mathrm{mM})$ stimulated hemin release from oxyHb in time- and concentration-dependent manners. By incubation with $1 \mathrm{mM}$ HADNT for $60 \mathrm{~min}$, the rate of release of hemin from added oxyHb was $3.2 \%$ of the oxyHb added. However, a minimal release of hemin was detected by reaction with TNT at a concentration of $1 \mathrm{mM}$. When ADNT or AADNT was used instead of TNT, a similar result was also obtained (data not shown). With respect to metabolic rate of TNT, when TNT $(1 \mathrm{mM})$ was incubated with NADPH $(1 \mathrm{mM})$ and P450R $(4.2 \mu \mathrm{g} / \mathrm{mL})$ in $300 \mathrm{mM} \mathrm{KPi}(\mathrm{pH} 7.7)-0.1 \mathrm{mM}$ EDTA at $37^{\circ} \mathrm{C}$ for $30 \mathrm{~min}$, more than $0.1 \mathrm{mM}$ of HADNT was produced (data not shown). This also supports the notion that metabolic transformation to HADNT can be a cause of TNTmediated hematotoxicity.

\section{DISCUSSION}

The present study indicates that hematotoxicity of TNT requires reductive activation corresponding to formation of the 4-electron reduction metabolite HADNT. Oral administration of rats to TNT in vivo resulted in a significant metHb formation and decrease in the $\mathrm{Ht}$ val- 

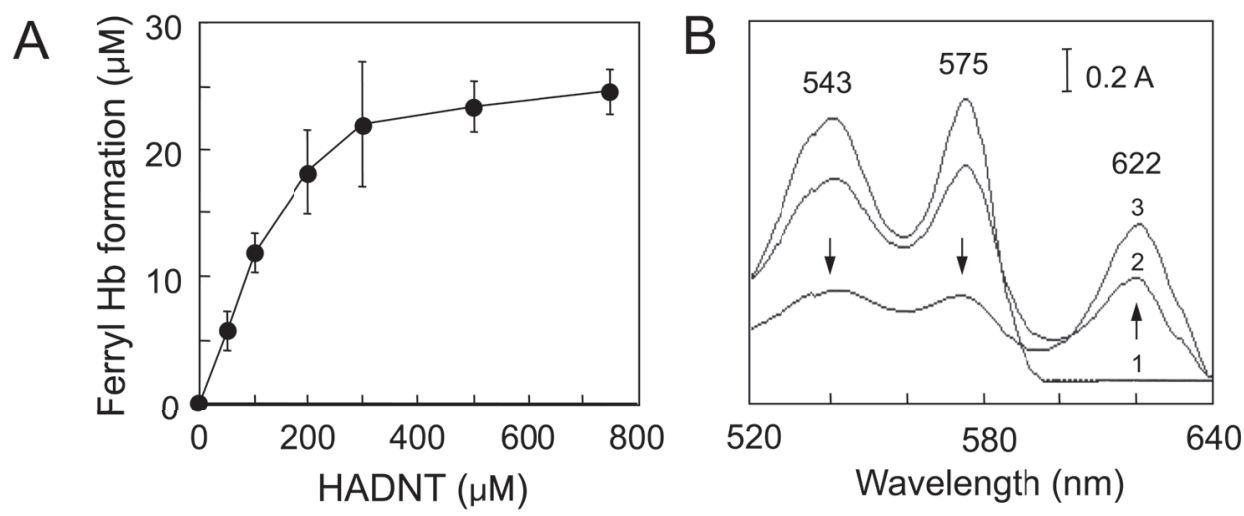

Fig. 3. FerrylHb formation (A) and the spectra of sulfHb formed (B) during the reaction of oxyHb with HADNT. A. OxyHb $(80 \mu \mathrm{M})$ was incubated with the indicated concentrations of HADNT in $20 \mathrm{mM} \mathrm{KPi}(\mathrm{pH} 7.0)$ at $25^{\circ} \mathrm{C}$ for $10 \mathrm{~min}$. Each value is the mean \pm S.D. of four determinations. B. OxyHb $(80 \mu \mathrm{M})$ was pre-incubated with sodium sulfide $(2 \mathrm{mM})$ at $25^{\circ} \mathrm{C}$ for $15 \mathrm{~min}$, and then incubated with HADNT $(1 \mathrm{mM})$ at $25^{\circ} \mathrm{C}$ for $15 \mathrm{~min}$ to convert the ferryl species into the sulfheme derivative. $1,0 \mathrm{~min} ; 2,0.5 \mathrm{~min} ; 3,15 \mathrm{~min}$.

ue (Fig. 1) but exposure of purified oxyHb or packed red blood cells to TNT did not mediate these hematotoxic actions. In contrast, incubation of oxyHb with HADNT, but not ADNT and AADNT, caused oxidation of metHb from oxyHb and hemolysis of red blood cells (Fig. 2). Under these conditions, only HADNT produced $\mathrm{H}_{2} \mathrm{O}_{2}$ and ferrylHb during reaction with oxyHb (Fig. 3). These findings suggest that HADNT, which can undergo reaction between the hydroxylamine group and the heme iron, is a major metabolite involved in metHb formation and hemolysis caused by TNT exposure in vivo. We speculate that metabolic transformation of TNT mainly occurs in the liver and that the expression levels of enzymes responsible for catalyzing reduction of TNT to HADNT such as P450R are quite low in the erythrocytes.

It has been reported that hydroxylamine analogs are reactive towards oxyHb to form metHb (Harrison and Jollow, 1986; Stolze et al., 1996; Reilly et al., 1999; Spooren and Evelo, 2000). In general, hydroxylamine and its derivatives are capable of forming metHb in the erythrocytes, together with a production of $\mathrm{H}_{2} \mathrm{O}_{2}$ during interaction with oxyHb (Spooren and Evelo, 2000). In addition, Kawanishi and Caughey (1985) reported that human oxyHb reacts with aquopentacyanoferrate (II) to yield $\mathrm{H}_{2} \mathrm{O}_{2}$-metHb via a formation of metHb-O-O-Fe(III) $(\mathrm{CN})_{5}^{3-}$. Based on these concepts, it is likely that interaction of oxyHb with HADNT resulted in formations of metHb- $\mathrm{H}_{2} \mathrm{O}_{2}$ and HADNT radical species; then, $\mathrm{H}_{2} \mathrm{O}_{2}$ was released from the heme moiety because the affinity of $\mathrm{H}_{2} \mathrm{O}_{2}$ to ferric form of heme was quite negligible. Formed $\mathrm{H}_{2} \mathrm{O}_{2}$ itself can also oxidize oxyHb to metHb (Kanias and Acker, 2010). In this case, however, a potent oxidizing agent ferrylHb, which is believed to mediate the peroxidation of lipids, proteins and nucleic acids (Newman et al., 1991; Everse and Hsia, 1997) was formed as a transient intermediate as shown in Fig. 3A. This reactive species of $\mathrm{Hb}$ was further confirmed as sulfHb in the presence of sodium sulfide (Fig. 3B).

It was reported that rat $\mathrm{Hb}$ is a hetero-tetramer consisting of 2 alpha-chains with 3 cysteine residues and 2 betachains with 2 cysteine residues (Chua et al., 1975; Satoh et al., 1987) but 6 thiol groups of 10 cysteine residues are active (Rossi et al., 1997). In the present study, reaction of oxyHb with HADNT resulted in a marked oxidation

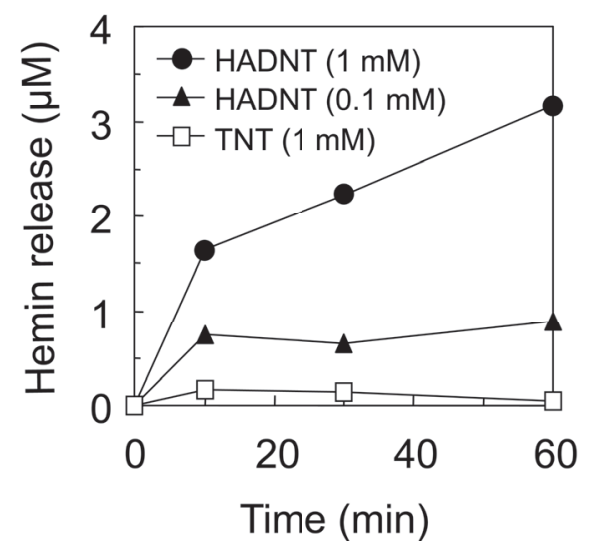

Fig. 4. Release of hemin during interaction of oxyHb with TNT or HADNT. OxyHb $(25 \mu \mathrm{M})$ was incubated with TNT $(1 \mathrm{mM})$ or HADNT $(0.1$ or $1 \mathrm{mM})$ in $20 \mathrm{mM}$ potassium phosphate buffer $(\mathrm{pH} 7.0)$ at $25^{\circ} \mathrm{C}$. After the reaction, $\mathrm{NaCl}$ was added to the reaction mixtures to make a final concentration of $1.5 \mathrm{M}$ and then the hemin released was determined. Each point is the average of two determinations. 
of globin sulfhydryls. In our preliminarily study, SDSPAGE in the absence of 2-mercaptoethanol revealed that the decreased thiol groups of oxyHb by HADNT were accompanied by cross-linking of $\mathrm{Hb}$ subunits through disulfide formation, thereby forming unusual polymer with high molecular weight presumably via intra-/intermolecular S-S binding (Song Li, unpublished observation). Davies et al. (Davies and Delsignore, 1987; Davies et al., 1987) reported that reactive oxygen species could be capable of oxidative modification of amino acids such as cysteine, thereby causing conformational alterations into protein molecules. The production of reactive oxygen species, including $\mathrm{H}_{2} \mathrm{O}_{2}$ and ferrylHb has been reported to be associated with extensive formation of disulfidelinked $\mathrm{Hb}$ adducts on red blood cell membrane skeletal proteins and disulfide-linked Hb polymers (Kiese, 1966; Grossman et al., 1992). Thus, a reasonable explanation is that $\mathrm{H}_{2} \mathrm{O}_{2}$ and/or ferrylHb generated by the interaction of oxyHb with HADNT potentially participates in the disulfide formation of the globin moiety, resulting in $\mathrm{Hb}$ aggregation.

The heme in metHb is more likely to dissociate from the pocket in the protein than the reduced heme in oxyHb that is tightly bound to the globin (Umbreit, 2007), thereby increasing release of hemin. Since hemin is known to be a potent hemolytic agent that nonspecifically impairs lipidprotein and protein-protein interactions in human erythrocytes (Kirschner-Zilber et al., 1982), we determined the release of hemin during the reaction of oxyHb with TNT or its metabolites. As expected, HADNT but not TNT, ADNT, and AADNT induced release of hemin from oxy$\mathrm{Hb}$ in time- and concentration-dependent manners (Fig. 4). To our knowledge, this is the first report to demonstrate dissociation of heme moiety from the $\mathrm{Hb}$ molecule caused by an active metabolite of TNT. Early studies on heme biosynthesis in erythroid tissue have indicated that hemin itself inhibits the production of delta-aminolevulinic acid, a precursor for heme, both in vivo and in vitro (Karibian and London, 1965; Gallo, 1967). On the other hand, hemin induces heme oxygenase, the rate-limiting enzyme for heme degradation (Tenhunen et al., 1970). These findings indicate that if hemin is released from the $\mathrm{Hb}$ molecule by TNT exposure, biosynthesis and decomposition of heme would be down-regulated and up-regulated, respectively, leading to a negative heme balance. Thus, the present findings suggest that TNT-mediated negative heme balance is, at least in part, due to release of hemin during interaction of oxyHb with HADNT derived from TNT.

In summary, the present findings suggest that prooxidants such as $\mathrm{H}_{2} \mathrm{O}_{2}$ and ferrylHb generated during interaction of oxyHb with HADNT formed from TNT play important roles in the metHb formation and decrease in the Ht value caused by TNT exposure in vivo. We also found that HADNT causes oxidation of globin sulfhydryls and heme release; as a consequence, aggregation of $\mathrm{Hb}$ and hemolysis appears to occur. We speculate that TNTinduced decrease in the Ht value is due to an increased removal of the damaged erythrocytes caused by HADNT in the spleen because Jollow et al. (1995) reported that the N-hydroxy metabolites of dapsone induce the premature sequestration of the damaged cells by the spleen.

\section{ACKNOWLEDGEMENTS}

This work was supported by a Grant-in-Aid (\#15K08042 to Y. S.) for scientific research from the Ministry of Education, Culture, Sports, Science and Technology of Japan.

Conflict of interest---- The authors declare that there is no conflict of interest.

\section{REFERENCES}

Ahlborg, G.Jr., Einistö, P. and Sorsa, M. (1988): Mutagenic activity and metabolites in the urine of workers exposed to trinitrotoluene (TNT). Br. J. Ind. Med., 45, 353-358.

Balla, J., Jacob, H.S., Balla, G., Nath, K., Eaton, J.W. and Vercellotti, G.M. (1993): Endothelial-cell heme uptake from heme proteins: induction of sensitization and desensitization to oxidant damage. Proc. Natl. Acad. Sci. USA, 90, 9285-9289.

Berzofsky, J.A., Peisach, J. and Blumberg, W.E. (1971): Sulfheme proteins. I. Optical and magnetic properties of sulfmyoglobin and its derivatives. J. Biol. Chem., 246, 3367-3377.

Beutler, E. (1969): Drug-induced hemolytic anemia. Pharmacol. Rev., 21, 73-103.

Biaglow, J.E., Varnes, M.E., Roizen-Towle, L., Clark, E.P., Epp, E.R., Astor, M.B. and Hall, E.J. (1986): Biochemistry of reduction of nitro heterocycles. Biochem. Pharmacol., 35, 77-90.

Channon, H.J., Mills, G.T. and Williams, R.T. (1944): The metabolism of 2:4:6-trinitrotoluene (alpha-T.N.T.). Biochem. J., 38, 70-85.

Chua, C.G., Carrell, R.W. and Howard, B.H. (1975): The amino acid sequence of the alpha chain of the major haemoglobin of the rat (Rattus norvegicus). Biochem. J., 149, 259-269.

Crawford, M.A. (1954): Aplastic anaemia due to trinitrotoluene intoxication. Br. Med. J., 2, 430-437.

Davies, K.J. and Delsignore, M.E. (1987): Protein damage and degradation by oxygen radicals. III. Modification of secondary and tertiary structure. J. Biol. Chem., 262, 9908-9913.

Davies, K.J., Lin, S.W. and Pacifici, R.E. (1987): Protein damage and degradation by oxygen radicals. IV. Degradation of denatured protein. J. Biol. Chem., 262, 9914-9920.

Djerassi, L.S. and Vitany, L. (1975): Haemolytic episode in G6 PD deficient workers exposed to TNT. Br. J. Ind. Med., 32, 54-58.

Evelyn, K.A. and Malloy, H.T. (1938): Microdetermination of oxyhemoglobin, methemoglobin, and sulfhemoglobin in a single sample of blood. J. Biol. Chem., 126, 655-662.

Everse, J. and Hsia, N. (1997): The toxicities of native and modified 
hemoglobins. Free Radic. Biol. Med., 22, 1075-1099.

Gallo, R.C. (1967): The inhibitory effect of heme on heme formation in vivo: possible mechanism for the regulation of hemoglobin synthesis. J. Clin. Invest., 46, 124-132.

Giulivi, C. and Davies, K.J. (1990): A novel antioxidant role for hemoglobin. The comproportionation of ferrylhemoglobin with oxyhemoglobin. J. Biol. Chem., 265, 19453-19460.

Grossman, S.J., Simson, J. and Jollow, D.J. (1992): Dapsone-induced hemolytic anemia: effect of N-hydroxy dapsone on the sulfhydryl status and membrane proteins of rat erythrocytes. Toxicol. Appl. Pharmacol., 117, 208-217.

Härkönen, H., Kärki, M., Lahti, A. and Savolainen, H. (1983): Early equatorial cataracts in workers exposed to trinitrotoluene. Am. J. Ophthalmol., 95, 807-810.

Harrison, J.H.Jr. and Jollow, D.J. (1986): Role of aniline metabolites in aniline-induced hemolytic anemia. J. Pharmacol. Exp. Ther., 238, 1045-1054.

Hathaway, J.A. (1977): Trinitrotoluene: a review of reported doserelated effects providing documentation for a workplace standard. J. Occup. Med., 19, 341-345.

Hebbel, R.P. and Eaton, J.W. (1989): Pathobiology of heme interaction with the erythrocyte membrane. Semin. Hematol., 26, 136-149.

Hildebraunt, A.G. and Roots, I. (1975): Reduced nicotinamide adenine dinucleotide phosphate (NADPH)-dependent formation and breakdown of hydrogen peroxide during mixed function oxidation reactions in liver microsomes. Arch. Biochem. Biophys., 171, 385-397.

Jollow, D.J., Bradshaw, T.P. and McMillan, D.C. (1995): Dapsoneinduced hemolytic anemia. Drug Metab. Rev., 27, 107-124.

Kanias, T. and Acker, J.P. (2010): Biopreservation of red blood cells--the struggle with hemoglobin oxidation. FEBS J., 277, 343-356.

Kappus, H. (1986): Overview of enzyme systems involved in bioreduction of drugs and in redox cycling. Biochem. Pharmacol., 35, 1-6.

Karibian, D. and London, I.M. (1965): Control of heme synthesis by feedback inhibition. Biochem. Biophys. Res. Commun., 18, 243-249.

Karuzina, II, Zgoda, V.G., Kuznetsova, G.P., Samenkova, N.F. and Archakov, A.I. (1999): Heme and apoprotein modification of cytochrome P450 2B4 during its oxidative inactivation in monooxygenase reconstituted system. Free Radic. Biol. Med., 26, 620-632.

Kawanishi, S. and Caughey, W.S. (1985): Mechanism of electron transfer to coordinated dioxygen of oxyhemoglobins to yield peroxide and methemoglobin. Protein control of electron donation by aquopentacyanoferrate(II). J. Biol. Chem., 260, 4622-4631.

Kiese, M. (1966): The biochemical production of ferrihemoglobinforming derivatives from aromatic amines, and mechanisms of ferrihemoglobin formation. Pharmacol. Rev., 18, 1091-1161.

Kirschner-Zilber, I., Rabizadeh, E. and Shaklai, N. (1982): The interaction of hemin and bilirubin with the human red cell membrane. Biochim. Biophys. Acta, 690, 20-30.

Kovacic, P. and Somanathan, R. (2014): Nitroaromatic compounds: Environmental toxicity, carcinogenicity, mutagenicity, therapy and mechanism. J. Appl. Toxicol., 34, 810-824.

Kumagai, Y., Todaka, T. and Toki, S. (1990): A new metabolic pathway of morphine: in vivo and in vitro formation of morphinone and morphine-glutathione adduct in guinea pig. J. Pharmacol. Exp. Ther., 255, 504-510.

Leung, K.H., Yao, M., Stearns, R. and Chiu, S.H. (1995): Mecha- nism of bioactivation and covalent binding of 2,4,6-trinitrotoluene. Chem. Biol. Interact., 97, 37-51.

Levine, B.S., Furedi, E.M., Gordon, D.E., Lish, P.M. and Barkley, J.J. (1984): Subchronic toxicity of trinitrotoluene in Fischer 344 rats. Toxicology, 32, 253-265.

Li, S., Kumagai, Y., Kiriya-Sakai, M. and Shimojo, N. (1998): [Acetylation of 4-amino-2,6-dinitrotoluene, a major metabolite of 2,4,6-trinitrotoluene by liver cytosol of SD rats]. Sangyo Eiseigaku Zasshi, 40, 252-253.

Liu, S.C., Zhai, S. and Palek, J. (1988): Detection of hemin release during hemoglobin S denaturation. Blood, 71, 1755-1758.

MacGookin, A., Swift, S.R. and Tittensor, E. (1940): Orientation problems. Part III. 4,6-Dinitritoluene. J. Soc. Chem. Ind., 59, 92-94.

Newman, E.S., Rice-Evans, C.A. and Davies, M.J. (1991): Identification of initiating agents in myoglobin-induced lipid peroxidation. Biochem. Biophys. Res. Commun., 179, 1414-1419.

Reilly, T.P., Woster, P.M. and Svensson, C.K. (1999): Methemoglobin formation by hydroxylamine metabolites of sulfamethoxazole and dapsone: implications for differences in adverse drug reactions. J. Pharmacol. Exp. Ther., 288, 951-959.

Rossi, R., Lusini, L., Giannerini, F., Giustarini, D., Lungarella, G. and Di Simplicio, P. (1997): A method to study kinetics of transnitrosation with nitrosoglutathione: reactions with hemoglobin and other thiols. Anal. Biochem., 254, 215-220.

Sabbioni, G., Liu, Y.Y., Yan, H. and Sepai, O. (2005): Hemoglobin adducts, urinary metabolites and health effects in 2,4,6-trinitrotoluene exposed workers. Carcinogenesis, 26, 1272-1279.

Satoh, H., Fujii, H. and Okazaki, T. (1987): Molecular cloning and sequence analysis of two rat major globin cDNAs. Biochem. Biophys. Res. Commun., 146, 618-624.

Savolainen, H., Tenhunen, R. and Harkonen, H. (1985): Reticulocyte haem synthesis in occupational exposure to trinitrotoluene. Br. J. Ind. Med., 42, 354-355.

Schacter, L.P. (1986): Generation of superoxide anion and hydrogen peroxide by erythrocytes from individuals with sickle trait or normal haemoglobin. Eur. J. Clin. Invest., 16, 204-210.

Spooren, A.A. and Evelo, C.T. (2000): A study on the interaction between hydroxylamine analogues and oxyhemoglobin in intact erythrocytes. Blood Cells Mol. Dis., 26, 373-386.

Stolze, K., Dadak, A., Liu, Y. and Nohl, H. (1996): Hydroxylamine and phenol-induced formation of methemoglobin and free radical intermediates in erythrocytes. Biochem. Pharmacol., 52, 1821-1829.

Tenhunen, R., Marver, H.S. and Schmid, R. (1970): The enzymatic catabolism of hemoglobin: stimulation of microsomal heme oxygenase by hemin. J. Lab. Clin. Med., 75, 410-421.

Tenhunen, R., Zitting, A., Nickels, J. and Savolainen, H. (1984): Trinitrotoluene-induced effects on rat heme metabolism. Exp. Mol. Pathol., 40, 362-366.

Umbreit, J. (2007): Methemoglobin--it's not just blue: a concise review. Am. J. Hematol., 82, 134-144.

Winterbourn, C.C. (1990): Oxidative reactions of hemoglobin. Methods Enzymol., 186, 265-272.

Woollen, B.H., Hall, M.G., Craig, R. and Steel, G.T. (1986): Trinitrotoluene: assessment of occupational absorption during manufacture of explosives. Br. J. Ind. Med., 43, 465-473.

Yoshida, Y., Kashiba, K. and Niki, E. (1994): Free radical-mediated oxidation of lipids induced by hemoglobin in aqueous dispersions. Biochim. Biophys. Acta, 1201, 165-172. 